\title{
Entomological survey in two communes with residual malaria transmission in Gia Lai Province in the central highlands of Vietnam
}

Thai Quang Nguyen ', Manh Duc Nguyen', Vinh Xuan Pham', Huan Mah Ro², Michael D. Edstein ${ }^{3}$, Weng K. Chow ${ }^{3}$, Nicholas J. Martin ${ }^{4}$, Jeffrey C. Hertz ${ }^{4}$ and Maysa T. Motoki ${ }^{5,6^{*}}$ (D)

\begin{abstract}
Background: In 2018, the National Malaria Control Programme in Vietnam switched from prioritizing malaria control to elimination. However, with the ongoing elimination programme, there are still areas where residual malaria transmission persists, including the central highlands. This entomological survey was conducted to evaluate Anopheles diversity and host-seeking activity of Anopheles vectors in two communes with very low malaria transmission in Gia Lai Province.
\end{abstract}

Methods: Anopheles species were collected in la DReh commune and la KDam commune, Gia Lai Province in the central highlands of Vietnam. Collections were conducted using human-baited double net trap, light trap and manual aspiration collections around cattle sheds, in the dry and rainy season. Mosquito specimens were identified morphologically, and members of species complexes were distinguished molecularly. Mosquito night-feeding patterns were investigated during the dry and rainy seasons.

Results: Overall, 18,835 specimens including 19 taxa were collected in la KDam and la DReh communes. These included the primary malaria vectors, Anopheles dirus and Anopheles minimus, and other secondary vector species. Anopheles dirus was observed to be an anthropophilic species, whereas An. minimus and a number of secondary vectors were observed to be zoophilic. Anopheles vagus was the dominant species, followed by Anopheles sinensis and Anopheles peditaeniatus. The majority of specimens were collected in the rainy season due to the relatively large number of An. vagus, while An. peditaeniatus, An. dirus, Anopheles kochi, Anopheles monstrosus and Anopheles tessellatus were collected in greater numbers during the dry season. The peak of host-seeking activity for An. dirus, An. sinensis, and An. vagus was between 18.00 and $19.00 \mathrm{~h}$.

Conclusion: This study provided information on the diversity, seasonal prevalence and behaviour of Anopheles at the study sites. Identifying the diverse mosquito fauna in the central highlands of Vietnam allows species-specific control measures to be implemented by the National Programme to reduce malaria in areas of very low malaria transmission. The peak Anopheles host-seeking activity observed in this study was between 18.00 and $23.00 \mathrm{~h}$, which highlights the need to better characterize Anopheles behaviour in this region of Vietnam to inform on vector control strategies.

Keywords: Anopheles diversity, Host-seeking activity, Malaria, Vietnam

*Correspondence: maysatm@gmail.com

${ }^{5}$ Vysnova Partners Inc, Landover, MD, USA

Full list of author information is available at the end of the article

\section{Background}

Currently, the primary goal of Vietnam's National Malaria Control Programme (NMCP) is to eliminate malaria by 2030 [1]. The NMCP recommends the use original author(s) and the source, provide a link to the Creative Commons licence, and indicate if changes were made. The images or other third party material in this article are included in the article's Creative Commons licence, unless indicated otherwise in a credit line to the material. If material is not included in the article's Creative Commons licence and your intended use is not permitted by statutory regulation or exceeds the permitted use, you will need to obtain permission directly from the copyright holder. To view a copy of this licence, visit http://creativecommons.org/licenses/by/4.0/. The Creative Commons Public Domain Dedication waiver (http://creativeco mmons.org/publicdomain/zero/1.0/) applies to the data made available in this article, unless otherwise stated in a credit line to the data. 
of insecticide-treated nets (ITNs), long-lasting insecticide nets (LLINs), social mobilization, targeted residual indoor spraying, and improved anti-malarial drug treatment. These strategies significantly reduced the spread of malaria in many areas in the country [2-4]. However, despite these measures, there remain residual malaria transmission areas, predominately in forested regions of central and southern Vietnam [5-10]. These very low malaria transmission areas harbour primary malaria vectors and there are reports that long-lasting insecticidal net (LLIN) use is less common $[11,12]$. In deforested rural areas, where land has been cleared for cultivation, many secondary malaria vectors are present and may contribute to maintaining malaria transmission outside of forested areas [10].

Some members of the Anopheles dirus complex, Maculatus Group, and Hyrcanus Group have been recognized as malaria vectors in Southeast Asia [10, 13]. There are over 64 Anopheles species in Vietnam [14]. Anopheles dirus, Anopheles minimus, Anopheles epiroticus, and Anopheles sundaicus have been identified as the primary malaria vectors $[10,13,15,16]$, while many other species (Anopheles aconitus, Anopheles barbirostris, Anopheles campestris, Anopheles harrisoni, Anopheles indefinitus, Anopheles jeyporiensis, Anopheles maculatus, Anopheles nimpe, Anopheles nivipes, Anopheles peditaeniatus, Anopheles philippinensis, Anopheles sawadwongporni, Anopheles sinensis, Anopheles subpictus, and Anopheles vagus) are considered secondary malaria vectors $[10,16]$.

Correctly identifying the mosquito fauna in malariaendemic areas is critical to implementing species-specific control measures and other public health interventions. The identification of mosquito vectors is mainly based on morphological diagnostic characters. However, misidentifications of closely related species, with overlapping morphological characters, is possible and is more likely amongst sibling vector species [17]. In these circumstances, molecular identification has been used for definitive identification [18-21].

In Gia Lai Province, in the central highlands of Vietnam, there are many individuals who depend on the forest, forest fringe and deforested areas for subsistence (agriculture and wood cutting activities) with potential exposure to malaria vectors [22]. In 2020, Krong Pa was the most impacted district with 459 malaria cases, while 43 cases were reported in Ia Pa District (Gia Lai Province Center for Disease Control and Prevention-CDC pers. comm.). A survey of Anopheles vectors was conducted in 2019 to inform vector control strategies in residual malaria transmission areas of Gia Lia Province. The study focused on characterizing diversity and host-seeking activity of Anopheles vectors in Gia Lai Province.

\section{Methods}

\section{Study sites}

Gia Lai is a mountainous province in the northern region of the central highlands of Vietnam (Fig. 1), and has a tropical monsoon climate, and two distinctive seasons: the rainy season (May to October) and the dry season (November to April). The average annual rainfall is $2100 \mathrm{~mm}$ to $2200 \mathrm{~mm}$, the average temperature is $22^{\circ} \mathrm{C}$ to $25^{\circ} \mathrm{C}$ and the average annual air humidity is about $80 \%$ (Gia Lai Province Local Health Office, pers. comm.).

Entomological surveys were conducted during the rainy and dry seasons in Ia DReh (IDR) commune, Krong Pa District, and in Ia KDam (IKD) commune, Ia Pa District, Gia Lai Province (Fig. 1). Village sites (inside the villages) are those where people live. Village sites contain houses and small gardens with few trees; whereas farm (mixed with cassava, sugar cane and watermelon plantations) and forest sites (tropical dense forest in IDR and deforested area in IKD) are places where villagers conduct agriculture and forestry activities, but are not permanent residences (TQN pers. obsv.). IDR commune is 110-140 m above sea level and includes 8 villages: Hvut, Nai, Drai, Hyu, Djrong, Tring, Bau, and Chum Kia. There is a nature reserve named Ea So, which is comprised of dense tropical forest approximately $10 \mathrm{~km}$ from the villages. IKD commune is located $232 \mathrm{~m}$ above sea level, and includes deforested and open areas used for farming purposes. This commune comprises 7 villages: Hbel, Plei Toan 1, Plei Toan 2, Plei KDam 1, Plei Kdam 2, Bau, and Chroh Ko. In 2020, the population was 5,363 people in IDR (2642 women, 2721 men) and 4176 people in IKD (2341 women, 1835 men). In both communes, 30\% of population were between 15 and 49 years old. In the last years, the strategies of vector control have been the use of LLINs and insecticide-treated nets (ITNs), where IDR has been supplied with LLINs, and IKD with LLINs and ITNs (Gia Lai Province, CDC pers. comm.).

In 2019, 103 and 131 symptomatic malaria cases confirmed by blood film microscopy were reported in IDR and IKD communes, respectively (Gia Lai Province, CDC pers. comm.). The annual parasite incidence was 21.2 (103/4.857) cases per 1000 populations for the IDR commune and $35.2(131 / 3.717)$ cases per 1000 populations for the IKD commune. Based on the annual parasite incidence $<100$ cases per 1000 populations, both communes would be classified as areas of very low malaria transmission [23].

\section{Anopheles collection}

Entomology surveys were conducted in the dry season (1-28 January, 2019) and in the rainy season (29 June-24 July, 2019). During each survey, mosquitoes were collected in both communes, IDR and IKD, using light traps 


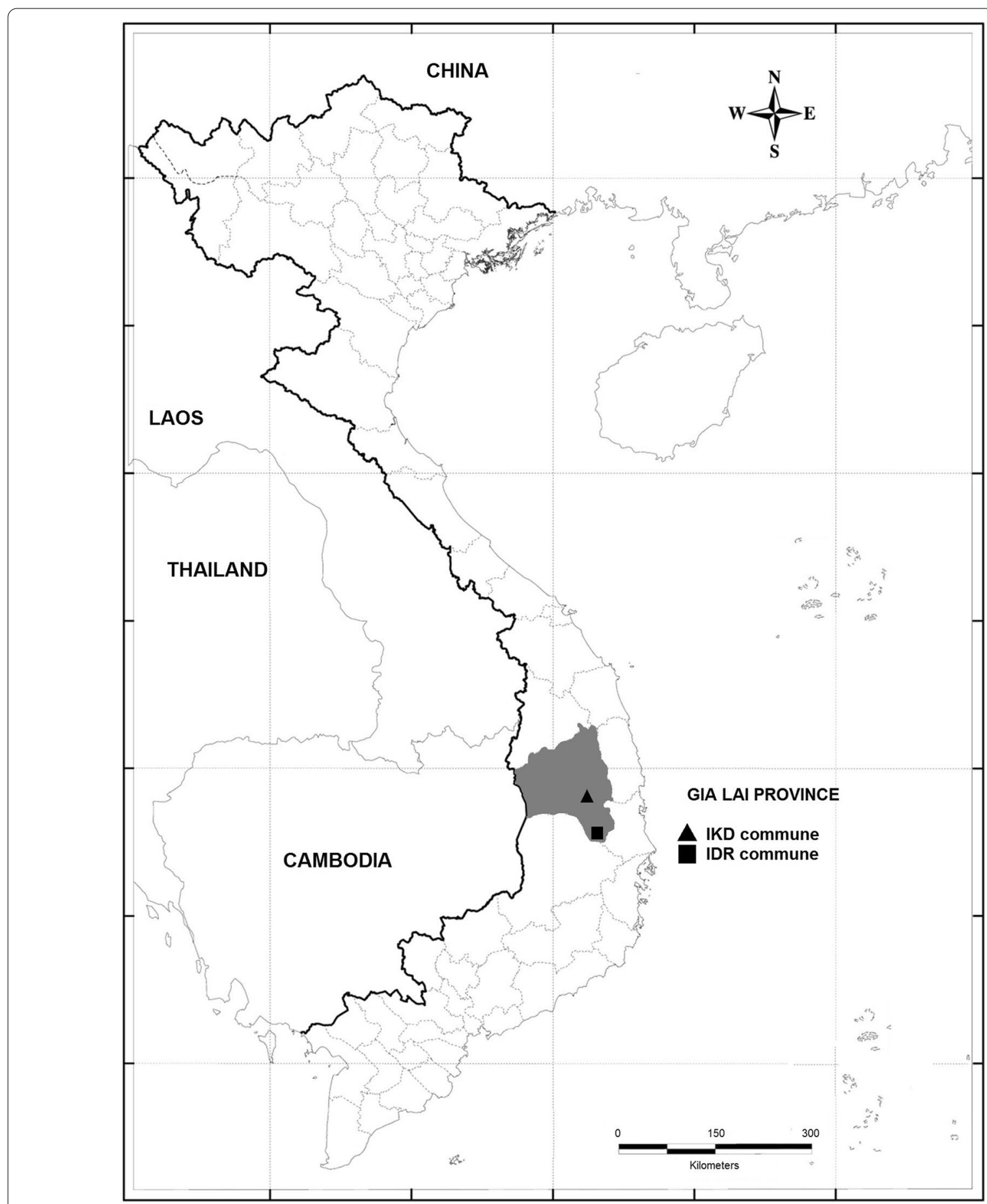

Fig. 1 Map of study sites in Gia Lai Province, Vietnam. IKD la KDam commune; la Pa district; IDR la DReh commune, Krong Pa district

(LT) from 18.00 to $06.00 \mathrm{~h}$, human-baited double net traps (HDN) [24], and using manual aspirations around cattle sheds (CS) from 18.00 to $24.00 \mathrm{~h}$. HDN and CS collections were conducted by one collector (i.e., one collector per trap/method).
For surveys in villages sites, during each season, one indoor HDN and one outdoor HDN was set up for 18 nights; CS collections were conducted for 24 nights; and LT collections were set up indoors $(n=2)$ and outdoors $(\mathrm{n}=2)$ for 18 nights in IDR and IKD. For surveys in farm 
and forest sites, one outdoor HDN was set up for 10 nights at IDR and IKD during each season; CS collections were conducted for two nights during the rainy season in IDR, whereas in IKD were conducted for three nights during the dry season and for four nights during the rainy season; no LT was set up in IDR, whereas two LTs were set up in IKD for five nights only during the rainy season.

\section{Anopheles identification}

Mosquitoes were morphologically identified under stereomicroscopes using keys developed by the National Institute of Malariology, Parasitology and Entomology [25]. Molecular methods were used for the identification of species complex/group members, except Barbirostris Complex was not identified molecularly, it was identified by morphological characters as An. barbirostris sensu lato (s.l.). DNA from head and prothorax of collected mosquito specimens was extracted using the QIAamp DNA Mini Kit-DNA Purification from Tissues as described in the manufacturer's instructions (Qiagen, Hilden, Germany). To identify species complex or group of Anopheles, the molecular methods used are those described by Garros et al. for the Funestus Group [26]; Huong et al. for the Dirus Complex [27]; and Walton et al. for the Maculatus Group [20]. Specimen identification was recognized according to the length of the product for each polymerase chain reaction (PCR)-based identification (Table 1).
For the PCR-based identification for the Funestus Group [26], each PCR contained $1.8 \mu$ of DNA template, $12.5 \mu \mathrm{l}$ of PCR master mix $2 \mathrm{x}$ (containing 0.5 units of Taq DNA polymerase, $200 \mu \mathrm{M}$ of dNTPs, $2.5 \mathrm{mM}$ of $\mathrm{MgCl}_{2}$ ), $0.16 \mu \mathrm{M}$ of each primer (ITS2A, MIA, MIC, ACO, VAR, PAM) (Table 1) made up to a total volume of $25 \mu \mathrm{l}$ using double distilled water $\left(\mathrm{ddH}_{2} \mathrm{O}\right)$. The PCR cycle was $94{ }^{\circ} \mathrm{C}$ for $2 \mathrm{~min}, 40$ cycles of $94{ }^{\circ} \mathrm{C}$ for $30 \mathrm{~s}, 45^{\circ} \mathrm{C}$ for $30 \mathrm{~s}$ and $72{ }^{\circ} \mathrm{C}$ for $40 \mathrm{~s}, 1$ cycle of $72{ }^{\circ} \mathrm{C}$ for $5 \mathrm{~min}$ and a $10^{\circ} \mathrm{C}$ hold. Five $\mu \mathrm{l}$ of the product was then run on $3 \%$ gel agarose and the results visualized by ultraviolet (UV) light.

For the PCR-based identification for the Dirus Complex [27], each PCR performed (a total of $50 \mu \mathrm{l}$ ), contained $200 \mu \mathrm{M}$ dNTPs each, $5 \mu \mathrm{l}$ of $10 \times$ PCR buffer (100 mM Tris-HCl, $500 \mathrm{mM} \mathrm{KCl,} 15 \mathrm{mM} \mathrm{MgCl} 2,0.1 \%$ gelatin; pH 9.5), $1 \mu \mathrm{M}$ (FA2/RA2, FD1/RD1), $1 \mu \mathrm{M}$ (FB2/ RB2), $1 \mu \mathrm{M}$ (FC3/RD3) of each primer, and $5 \mu$ of DNA template. The mixture was preheated for $2 \mathrm{~min}$ at $94{ }^{\circ} \mathrm{C}$, then $1 \mu \mathrm{l}$ of Taq DNA polymerase was added at $72^{\circ} \mathrm{C}$ followed by 30 cycles of amplification at $95^{\circ} \mathrm{C}$ for $15 \mathrm{~s}, 60^{\circ} \mathrm{C}$ for $15 \mathrm{~s}, 72{ }^{\circ} \mathrm{C}$ for $15 \mathrm{~s}$ and a final extension step at $72{ }^{\circ} \mathrm{C}$ for $5 \mathrm{~min}$. Five $\mu \mathrm{l}$ of the product was then run on 3\% gel agarose with the results visualized by UV light.

For PCR-based identification for the Maculatus Group [20], each PCR contained $1 \mu \mathrm{l}$ of DNA template, $12.5 \mu \mathrm{l}$ of PCR master mix 2x (containing 0.5 units of Taq DNA polymerase, $200 \mu \mathrm{M}$ of dNTPs, $2.5 \mathrm{mM}$ of

Table 1 Primers used in this study for the molecular identification of Anopheles complex/group members in village and farm/forest sites in la DReh commune, Krong Pa district, and la KDam commune, la Pa district, Gia Lai Province, Vietnam

\begin{tabular}{|c|c|c|c|c|}
\hline Species & Primer name & Sequence $\left(5^{\prime}-3\right)$ & PCR size & References \\
\hline Universal forward primer & ITS2A & 5'TGT GAA CTG CAG GAC ACA T 3' & & Garros et al. [26] \\
\hline An. minimus & MIA & 5' CCC GTG CGA CTT GAC GA 3' & 310-bp & Garros et al. [26] \\
\hline An. harrisoni & $\mathrm{MIC}$ & 5' GTT CAT TCA GCA ACA TCA GT 3' & 180-bp & Garros et al. [26] \\
\hline An. aconitus & $\mathrm{ACO}$ & 5’ ACA GCG TGT ACG TCC AGT 3’ & 200-bp & Garros et al. [26] \\
\hline An. varuna & VAR & 5'TTG ACC ACT TTC GAC GCA 3' & 260-bp & Garros et al. [26] \\
\hline An.pampanai & PAM & 5'TGT ACA TCG GCC GGG GTA 3' & $90-b p$ & Garros et al. [26] \\
\hline \multirow[t]{2}{*}{ An. $\operatorname{dirus}(A)$} & FA2 & 5'TCG GGT TCT ATA ATA TTC GCT 3' & $120-b p$ & Huong et al. [27] \\
\hline & RA2 & 5’ GAC CTA GTG TTT GGG AAG GT3’ & & \\
\hline \multirow[t]{2}{*}{ An. cracens } & FB2 & 5' GCTTCA AGA CCA AAA CCA TCA3' & 75-bp & Huong et al. [27] \\
\hline & RB2 & 5' GAA TTT ACA ACT TTT GAC CTG G3' & & \\
\hline \multirow[t]{2}{*}{ An. scanloni (C) } & FC3 & 5' ATT CTG TGC CAA AAT TGT ACC T3' & $60-b p$ & Huong et al. [27] \\
\hline & $\mathrm{RC} 3$ & 5'TTG TCC GAA ACT GGC TTC T 3' & & \\
\hline \multirow[t]{2}{*}{ An. baimaii } & FD1 & 5' AGG GCA CAA AAG TTA TTA ACT T 3' & 172-bp & Huong et al. [27] \\
\hline & RD1 & 5' GTG AAG AGC GAA TAT TGT AGC 3' & & \\
\hline Universal forward primer & $5.8 \mathrm{~F}$ & 5’ ATC ACT CGG CTC GTG GAT CG 3' & & Walton et al. [20] \\
\hline An. maculatus & MAC & 5' GAC GGT CAG TCT GGT AAA GT 3' & 180-bp & Walton et al. [20] \\
\hline An.pseudowillmori & PSEU & 5' GCC CCC GGG TGT CAA ACA G 3' & 203-bp & Walton et al. [20] \\
\hline An. sawadwongporni & SAW & 5' ACG GTC CCG CAT CAG GTG C 3' & 242-bp & Walton et al. [20] \\
\hline An. rampae (form k) & K & 5'TTC ATC GCT CGC CCTTAC AA 3' & 301-bp & Walton et al. [20] \\
\hline An. dravidicus & DRAV & 5' GCC TAC TTT GAG CGA GAC CA 3' & 477-bp & Walton et al. [20] \\
\hline
\end{tabular}


$\mathrm{MgCl}_{2}$ ), $0.4 \mu \mathrm{M}$ of each primer (5.8F, MAC, DRAV, K, SAW, PSEU) [20] made up to a total volume of $25 \mu \mathrm{l}$ using $\mathrm{ddH}_{2} \mathrm{O}$. The PCR cycle was $95{ }^{\circ} \mathrm{C}$ for $15 \mathrm{~min}, 35$ cycles of $94{ }^{\circ} \mathrm{C}$ for $1 \mathrm{~min}, 61{ }^{\circ} \mathrm{C}$ for $30 \mathrm{~s}$ and $72{ }^{\circ} \mathrm{C}$ for $30 \mathrm{~s}, 1 \mathrm{cycle}$ of $72{ }^{\circ} \mathrm{C}$ for $5 \mathrm{~min}$ and a $10{ }^{\circ} \mathrm{C}$ hold. Five $\mu \mathrm{l}$ of the PCR product was run on 3\% gel agarose and the results visualized by UV light.

\section{Statistical analysis}

Considering the heterogeneous number of traps and number of collections, specific comparisons of each collection method between communes, and according to the season were employed. For statistical analysis, the Monte Carlo Method, or Fisher's Exact Test were used when the sample size was small. These statistical tests were conducted using IBM SPSS statistics, version 25 , with statistical significance defined as a $\mathrm{p}<0.05$.

\section{Study protocol review}

The Institute of Malariology, Parasitology and Entomology Quy Nhon Institutional Review Board (IMPE-QN IRB) determined this study to be exempt from the IRB review (number 16/VSR-NCDT); the determination was made based on the national guideline of the Vietnamese Ministry of Health IRB on ethics in biomedical research. The study protocol \# HRPO.NAMRU2.2020.0002-HDN Trap was reviewed by Naval Medical Research CenterAsia Human Research Protections Review Board and is in compliance with all applicable Federal regulations governing the protection of human subjects.

\section{Results}

\section{Anopheles diversity}

Overall, 18,835 mosquitoes were collected, including 14 taxa in IDR $(\mathrm{n}=9553)$ and 18 taxa in IKD $(\mathrm{n}=9282)$ (Table 2). Members of the Funestus Group were molecularly identified as An. minimus sensu stricto (s.s.), $A n$. aconitus, An. harrisoni, An. varuna, and An. pampanai.

Table 2 Anopheles specimens identified morphologically and molecularly in village and farm and forest sites in la DReh commune, Krong Pa district, and in la KDam commune, la Pa district, Gia Lai Province, Vietnam

\begin{tabular}{|c|c|c|c|c|c|}
\hline \multirow[t]{3}{*}{ Group/complex } & \multirow[t]{3}{*}{ Species } & \multicolumn{4}{|c|}{ Communes } \\
\hline & & \multicolumn{2}{|l|}{ IDR } & \multicolumn{2}{|l|}{ IKD } \\
\hline & & Morp. ID & Mol. ID & Morp. ID & Mol. ID \\
\hline Annularis group & An. philippinensis ${ }^{\mathrm{b}}$ & 7 & - & 4 & - \\
\hline Barbirostris complex & An. barbirostris s.l. ${ }^{b}$ & 20 & - & 121 & - \\
\hline \multirow[t]{2}{*}{ Dirus complex } & An. dirus ${ }^{\mathrm{a}}$ & 86 & 85 & 5 & 5 \\
\hline & $\mathrm{N} / \mathrm{I}$ & 0 & 1 & 0 & - \\
\hline \multirow[t]{6}{*}{ Funestus group } & An. aconitus ${ }^{b}$ & 53 & 53 & 97 & 92 \\
\hline & An. minimus ${ }^{\mathrm{a}}$ & 0 & - & 143 & 119 \\
\hline & An. harrisonib & 0 & - & 0 & 3 \\
\hline & An. varuna & 0 & - & 0 & 21 \\
\hline & An.pampanai & 0 & - & 0 & 2 \\
\hline & $\mathrm{N} / \mathrm{I}$ & 0 & - & 0 & 3 \\
\hline \multirow[t]{2}{*}{ Hyrcanus group } & An. peditaeniatus ${ }^{\mathrm{b}}$ & 373 & - & 378 & - \\
\hline & An. sinensis ${ }^{b}$ & 534 & - & 412 & - \\
\hline \multirow[t]{2}{*}{ Jamesii group } & An.jamesii & 9 & - & 27 & - \\
\hline & An. splendidus & 14 & - & 1 & - \\
\hline Kochi group & An. kochi & 73 & - & - & - \\
\hline \multirow[t]{3}{*}{ Maculatus group } & An. maculatus ${ }^{b}$ & 23 & 1 & 224 & 5 \\
\hline & An. sawadwongpornib & 0 & 22 & 0 & 218 \\
\hline & An. rampae & 0 & - & 0 & 1 \\
\hline Subpictus group & An. vagus ${ }^{\mathrm{b}}$ & 8016 & - & 7643 & - \\
\hline Tessellatus group & An.tessellatus & 163 & - & 87 & - \\
\hline \multirow[t]{2}{*}{ No Group/complex } & An. monstrosus & 182 & - & 140 & - \\
\hline & Total & 9553 & & 9282 & \\
\hline
\end{tabular}

IDR la DReh commune, IKD la KDam commune, Morp. ID morphological identification, Mol. ID molecular identification, $N / I$ could not be identified molecularly

${ }^{\text {a }}$ Main malaria vectors

${ }^{\text {b }}$ Secondary malaria vectors according to the WHO [16], and Do Manh et al. [10] 
Three samples could not be identified to species. For the Maculatus Group, An. maculatus s.s., An. sawadwongporni and An. rampae were identified. For the Dirus Complex, only $A n$. dirus s.s. was recognized, and one sample could not be identified to species (Table 2).

Anopheles kochi was found only in IDR, while An. harrisoni, An. minimus, An. pampanai, An. rampae and An. varuna were unique to IKD (Table 2). Anopheles dirus were more common in IDR, while An. barbirostris s.l. and An. sawadwongporni were more common in IKD (Table 2). The three most common species collected in both communes were An. vagus, An. sinensis and $A n$. peditaeniatus (Table 2).

\section{Density and comparison of mosquitoes according to each collection method}

Anopheles vagus was collected in high density using CS (85.0\%, 15,193/17,871), HDN (48.8\%, 230/471), and LT (47.9\%, 236/493) (Tables 3-5). The remaining Anopheles collected by CS included 18 taxa, ranging from 1 to 831 specimens (Table 3). In the village site in IDR, CS collected more mosquito specimens $(54.4 \%, 8909 / 16,376)$ than in IKD $(45.6 \%, 7467 / 16,376)(\mathrm{p}<0.05$, Monte Carlo Method) (Table 3). Due to the heterogeneity of the number of collection traps and bad weather conditions, no comparison was made in farm/forest sites.

In addition to An. vagus collected using $\mathrm{HDN}, A n$. dirus represented 18.7\% (88/471), An. sinensis, 8\% (38/471), An. tessellatus, 7.0\% (33/471), An. peditaeniatus and An. sawadwongporni, $6.6 \%(31 / 471)$ of each species, with the remaining mosquitoes collected belonging to the other species listed in Table 4 . In village sites, HDN collected more mosquito specimens in IKD $(74.6 \%, 156 / 209)$ than in IDR $(25.4 \%, 53 / 209)$ ( $p<0.05$, Fisher Exact Test), while in farm and forest sites, mosquito specimens were collected more in IDR $(56.9 \%, 149 / 262)$ than in IKD $(43.1 \%$, 113/262) $(\mathrm{p}<0.05$, Fisher Exact Test) (Table 4).

The LT collected 493 specimens. In addition to $A n$. vagus, $21.3 \%$ (105/493) were An. peditaeniatus, and $15.6 \%$ (77/493) were An. sinensis. The remaining 13.2\% of specimens collected in LT included 12 additional species at low collection densities (Table 5). Anopheles kochi were found only in the village sites (Tables 3-5); while An. dirus, An. harrisoni, An. maculatus, An. minimus, An. pampanai, An. rampae, and An. varuna, were collected only in farm or forest sites (Tables $3-5$ ). In village sites, LTs collected more mosquitoes $(63.8 \%, 292 / 458)$ in IKD than in IDR $(36.2 \%, 166 / 458)(\mathrm{p}<0.05$, Monte Carlo Method) (Table 5). The lack of homogeneous LTs

Table 3 Number and percentage of Anopheles collected using CS in village and farm and forest sites in IDR and IKD communes

\begin{tabular}{|c|c|c|c|c|c|c|}
\hline \multirow[t]{2}{*}{ Species } & \multicolumn{2}{|c|}{ la DReh } & \multicolumn{2}{|c|}{ Ia KDam } & \multirow[t]{2}{*}{ Total } & \multirow[t]{2}{*}{$\%$} \\
\hline & v & $\mathbf{F}$ & V & $\mathbf{F}$ & & \\
\hline An. vagus & 7649 & 251 & 6687 & 606 & 15,193 & 85.0 \\
\hline An. sinensis & 489 & 20 & 308 & 14 & 831 & 4.65 \\
\hline An. peditaeniatus & 324 & 3 & 279 & 10 & 616 & 3.45 \\
\hline An. monstrosus & 174 & - & 131 & 1 & 306 & 1.71 \\
\hline An. sawadwongporni & 3 & - & - & 199 & 202 & 1.13 \\
\hline An. tessellatus & 128 & 1 & 61 & 11 & 201 & 1.12 \\
\hline An. barbirostris s.l & 17 & - & - & 119 & 136 & 0.76 \\
\hline An. aconitus & 37 & - & - & 85 & 122 & 0.68 \\
\hline An. minimus & - & - & - & 111 & 111 & 0.62 \\
\hline An. kochi & 67 & - & - & - & 67 & 0.37 \\
\hline An. jamesii & 9 & - & - & 25 & 34 & 0.19 \\
\hline An. varuna & - & - & - & 20 & 20 & 0.11 \\
\hline An. splendidus & 8 & 1 & - & 1 & 10 & 0.06 \\
\hline An. philippinensis & 4 & - & 1 & 3 & 8 & 0.04 \\
\hline An. maculatus & - & - & - & 5 & 5 & 0.03 \\
\hline An. harrisoni & - & - & - & 3 & 3 & 0.02 \\
\hline Anopheles sp. & - & - & - & 3 & 3 & 0.02 \\
\hline An.pampanai & - & - & - & 1 & 1 & 0.01 \\
\hline An. rampae & - & - & - & 1 & 1 & 0.01 \\
\hline An. dirus & - & - & - & 1 & 1 & 0.01 \\
\hline Total & 8909 & 276 & 7467 & 1219 & 17,871 & 100 \\
\hline
\end{tabular}

CS collection around cattle shed, $V$ village sites, $F$ farm and forest sites 
Table 4 Number and percentage of Anopheles collected using HDN in village and farm and forest sites in IDR and IKD communes

\begin{tabular}{|c|c|c|c|c|c|c|}
\hline \multirow[t]{2}{*}{ Species } & \multicolumn{2}{|c|}{ la DReh } & \multicolumn{2}{|c|}{ la KDam } & \multirow[t]{2}{*}{ Total } & \multirow[t]{2}{*}{$\%$} \\
\hline & v & $\mathbf{F}$ & v & $\mathbf{F}$ & & \\
\hline An. vagus & 40 & 7 & 115 & 68 & 230 & 48.8 \\
\hline An. dirus & - & 85 & - & 3 & 88 & 18.7 \\
\hline An. sinensis & 4 & - & 26 & 8 & 38 & 8.0 \\
\hline An. tessellatus & - & 22 & 2 & 9 & 33 & 7.0 \\
\hline An. sawadwongporni & - & 19 & - & 12 & 31 & 6.6 \\
\hline An.peditaeniatus & 7 & 1 & 12 & 10 & 30 & 6.5 \\
\hline An. aconitus & - & 9 & - & 1 & 10 & 2.0 \\
\hline An. barbirostris s.l & - & 2 & - & - & 2 & 0.5 \\
\hline An. monstrosus & - & 1 & 1 & - & 2 & 0.5 \\
\hline An. kochi & 1 & - & - & - & 1 & 0.2 \\
\hline An. maculatus & - & 1 & - & - & 1 & 0.2 \\
\hline An.minimus & - & - & - & 1 & 1 & 0.2 \\
\hline An.pampanai & - & - & - & 1 & 1 & 0.2 \\
\hline An.philippinensis & - & 1 & - & - & 1 & 0.2 \\
\hline An. splendidus & 1 & - & - & - & 1 & 0.2 \\
\hline Anopheles sp. & - & 1 & - & - & 1 & 0.2 \\
\hline Total & 53 & 149 & 156 & 113 & 471 & 100 \\
\hline
\end{tabular}

HDN human-baited double net trap, $V$ village sites, $F$ farm and forest sites

Table 5 Number and percentage of Anopheles collected using LT in village and farm and forest sites in IDR and IKD communes

\begin{tabular}{|c|c|c|c|c|c|c|}
\hline \multirow[t]{2}{*}{ Species } & \multicolumn{2}{|c|}{ la DReh } & \multicolumn{2}{|c|}{ la KDam } & \multirow[t]{2}{*}{ Total } & \multirow[t]{2}{*}{$\%$} \\
\hline & V & $\mathbf{F}$ & V & $\mathbf{F}$ & & \\
\hline An. vagus & 69 & - & 156 & 11 & 236 & 47.9 \\
\hline An.peditaeniatus & 38 & - & 67 & - & 105 & 21.3 \\
\hline An. sinensis & 21 & - & 56 & - & 77 & 15.6 \\
\hline An.tessellatus & 12 & - & 4 & - & 16 & 3.2 \\
\hline An. monstrosus & 7 & - & 7 & - & 14 & 2.8 \\
\hline An. aconitus & 7 & - & - & 6 & 13 & 2.6 \\
\hline An. minimus & - & - & - & 7 & 7 & 1.4 \\
\hline An. sawadwongporni & - & - & - & 7 & 7 & 1.4 \\
\hline An. kochi & 5 & - & - & - & 5 & 1 \\
\hline An. splendidus & 4 & - & - & - & 4 & 0.8 \\
\hline An. barbirostris s.l & 1 & - & - & 2 & 3 & 0.6 \\
\hline An.philippinensis & 2 & - & - & - & 2 & 0.4 \\
\hline An.jamesii & - & - & 2 & - & 2 & 0.4 \\
\hline An. dirus & - & - & - & 1 & 1 & 0.2 \\
\hline An. varuna & - & - & - & 1 & 1 & 0.2 \\
\hline Total & 166 & - & 292 & 35 & 493 & 100 \\
\hline
\end{tabular}

$L T$ light trap, $V$ village sites, $F$ farm and forest sites

distribution, due to animal movements, and the bad weather impaired the collection of mosquitoes using LT in farm/forest sites, therefore no comparison was made between farm and forest sites. Additional file 1 reported the number of Anopheles mosquitoes collected outdoor and indoor using HDN and LT.

\section{Seasonality}

Mosquitoes collected in village sites using $H D N, C S$, and $L T$ In village sites, in both IDR and IKD communes, species differed depending on the season, except An. sinensis (49 and $51 \%$ collected in dry and rainy seasons, respectively, in IKD) (Table 6). Anopheles aconitus, An. kochi, An. 
Table 6 Anopheles specimens collected during the dry and rainy season using CS, HDN, and LT, in village sites in la DReh and la KDam communes

\begin{tabular}{llllll}
\hline Species & \multicolumn{2}{l}{ la DReh commune } & & \multicolumn{2}{l}{$\begin{array}{l}\text { la KDam } \\
\text { commune }\end{array}$} \\
\cline { 2 - 3 } \cline { 5 - 6 } & DS & RS & & DS & RS \\
\hline An. aconitus & 44 & - & - & - \\
An. barbirostris & 17 & 1 & & - & - \\
An. jamesii & 8 & 1 & & - & 2 \\
An. kochi & 73 & - & & - & - \\
An. monstrosus & 181 & - & & 139 & - \\
An. peditaeniatus & 292 & 77 & & 265 & 93 \\
An. philippinensis & 2 & 4 & & - & 1 \\
An. sawadwongporni & 3 & - & & - \\
An. sinensis & 361 & 153 & & 193 & 197 \\
An. splendidus & 12 & 1 & & - \\
An. tessellatus & 137 & 3 & 65 & 2 \\
An. vagus & 1590 & 6168 & 1296 & 5662 \\
Total & 2720 & 6408 & 1958 & 5957 \\
\hline
\end{tabular}

CS collection around cattle shed, HDN human-baited double net trap, $L T$ light trap, $D S$ dry season, $R S$ rainy season

monstrosus, and An. sawadwongporni were collected only in the dry season in IDR, and An. monstrosus in IKD; while An. jamesii and An. philippinensis were collected only in the rainy season in IKD (Table 6). In the dry season An. barbirostris s.l. (94\%, 17/18), An. jamesii (89\%, 8/9), An. peditaeniatus (79\%, 292/369), An. sinensis (67\%, 361/514), An. splendidus (92\%, 12/13), and An. tessellatus $(98 \%, 137 / 140)$ in IDR, and An. peditaeniatus (74\% 265/358), and An. tessellatus (97\%, 65/67) in IKD were more abundant compared to the rainy season; whereas An. philippinensis $(67 \%, 4 / 6)$, and An. vagus (80\%, $6,168 / 7,758)$, were more common in the rainy season in IDR, and An. vagus $(81 \%, 5,662 / 6,958)$ in IKD (Table 6). Total Anopheles species collected in village sites were more common in the rainy season due to the high density of An. vagus (Table 6). When An. vagus was excluded, and comparisons were made between the other Anopheles mosquitoes, they are more abundant in the dry season at the two communes $(82.5 \%$ in IDR, $1,130 / 1,370$, and $69.2 \%$ in IKD, 662/957) $(\mathrm{p}<0.05$, Monte Carlo Method $)$ (Table 6).

\section{Mosquitoes collected in farm/forest sites using HDN}

In farm and forest sites, An. philippinensis were collected only in the dry season in IDR, and An. aconitus in IKD; while Anopheles barbirostris s.l., An. maculatus, An. peditaeniatus, and An. vagus were collected only in the rainy season in IDR, and An. minimus in IKD (Table 7). Anopheles aconitus (77.8\%, 7/9) and An. dirus (76.5\%,
Table 7 Anopheles specimens collected during the dry and rainy season using HDN in farm and forest sites in la DReh and la KDam communes

\begin{tabular}{llllll}
\hline Species & \multicolumn{2}{l}{ la DReh } & & \multicolumn{2}{l}{ la KDam } \\
\cline { 2 - 3 } \cline { 5 - 6 } & DS & RS & & DS & RS \\
\hline An. aconitus & 7 & 2 & 1 & - \\
An. barbirostris & - & 2 & - & - \\
An. dirus & 65 & 20 & 2 & 1 \\
An. maculatus & - & 1 & - & - \\
An. minimus & - & - & - & 1 \\
An. monstrosus & 1 & - & - & - \\
An. pampanai & - & - & - & 1 \\
An. peditaeniatus & - & 1 & 8 & 2 \\
An. philippinensis & 1 & - & - & - \\
An. sawadwongporni & 4 & 15 & 3 & 9 \\
An. sinensis & - & - & 2 & 6 \\
An. tessellatus & 22 & - & 8 & 1 \\
An. vagus & - & 7 & 29 & 39 \\
Total & 100 & 48 & 53 & 60 \\
\hline
\end{tabular}

$H D N$ human-baited double net trap, $D S$ dry season, $R S$ rainy season

$65 / 85)$ were more common in the dry season in IDR, and An. dirus $(67 \%, 2 / 3)$ and An. peditaeniatus $(80 \%, 8 / 10)$ in IKD; whereas An. sawadwongporni $(78.9 \%, 15 / 19)$ was more common in the rainy season in IRD, and $A n$. sawadwongporni $(75 \%, 9 / 12)$, An. sinensis $(75 \%, 6 / 8)$ and An. vagus $(57.4 \%, 39 / 68)$ in IKD (Table 7). In IDR, Anopheles mosquitoes were more abundant in the dry season $(67.6 \%, 100 / 148)$, while in IKD they were slightly more common in the rainy season $(53.1 \%, 60 / 113)(\mathrm{p}>0.05$, Fisher Exact Test) (Table 7). High density of An. dirus was captured using HDN in farm/forest sites in both dry and rainy season, following by An. tessellatus in the dry season and An. sawadwongporni in the rainy season. Anopheles vagus was found in both dry and rainy season at village, and farm and forest sites (Table 8).

\section{Observation on host-seeking activity of malaria vectors in humans (HDN) and cattle (CS)}

The observation of host-seeking activity for primary and secondary malaria vectors in seeking humans and cattle are shown in the Additional files 2 and 3. Malaria vectors collected in high density are presented in Figs. 2 and 3.

In IDR commune, the peak of host-seeking activity for $A n$. dirus collected using HDN in farm and forest sites occurred between 18.00 and 19.00 in the dry season (Fig. 2; Additional file 2). For mosquito species collected around CS in village sites, the peak occurred between 19.00 and 21.00 for An. vagus, between 19.00 and 22.00 for An. sinensis, and between 21.00 and 22.00 for An. peditaeniatus in the rainy season; in the dry season, the peak 
Table 8 HDN rates (number of mosquito/collector/night) for Anopheles species collected in village and farm and forest sites during the dry and rainy seasons in la DReh and la KDam communes

\begin{tabular}{|c|c|c|c|c|}
\hline \multirow[t]{2}{*}{ Species } & \multicolumn{2}{|c|}{ Village $^{a}$} & \multicolumn{2}{|c|}{ Farm/forest } \\
\hline & DS & RS & DS & RS \\
\hline An. aconitus & - & - & 0.080 & 0.020 \\
\hline An. barbirostris s.l & - & - & - & 0.020 \\
\hline An. dirus & - & - & 0.670 & 0.210 \\
\hline An. kochi & 0.003 & - & - & - \\
\hline An. maculatus & - & - & - & 0.010 \\
\hline An.minimus & - & - & - & 0.010 \\
\hline An. monstrosus & 0.003 & - & 0.010 & - \\
\hline An.peditaeniatus & 0.028 & 0.015 & 0.080 & 0.020 \\
\hline An.philippinensis & - & - & 0.010 & - \\
\hline An. sawadwongporni & - & - & 0.070 & 0.240 \\
\hline An. sinensis & 0.022 & 0.062 & 0.020 & 0.050 \\
\hline An. splendidus & 0.003 & - & - & - \\
\hline An. tessellatus & 0.006 & - & 0.300 & 0.010 \\
\hline An. vagus & 0.086 & 0.284 & 0.290 & 0.460 \\
\hline
\end{tabular}

$H D N$ human-baited double bed net trap, DS dry season, $R S$ rainy season

a Only outdoor trap was considered in the analysis

of host-seeking activity for $A n$. sinensis and $A n$. vagus occurred between 18.00 and 19.00, and between 20.00 and 21.00 for An. peditaeniatus (Fig. 2; Additional file 2). The peak of host-seeking for An. vagus collected in farm and forest sites during the rainy season was between 19.00 and 20.00 (Fig. 2; Additional file 2.

In village sites in IKD commune, the peak of host-seeking activity was between 20.00 and 21.00 for An. sinensis and $A n$. vagus during the rainy season; and between 19.00 and 20.00 for $A n$. An. sinensis and An. vagus, and between 20.00 and 21.00 for An. peditaeniatus in the dry season (Fig. 3; Additional file 3). In farm and forest sites of IKD, the peak of host-seeking activity was between 19.00 and 20.00 for An. barbirostris s.l., between 20.00 and 21.00 for An. vagus, between 21.00 and 22.00 for $A n$. aconitus and An. minimus, and between 22.00 and 23.00 for An. sawadwongporni in the rainy season. In the dry season, the peak for $A n$. vagus occurred between 18.00 and 19.00, and for An. sawadwongporni between 19.00 and 20.00 in the dry season (Fig. 3; Additional file 3).

\section{Discussion}

\section{Anopheles diversity and seasonality}

Herein, the two primary malaria vectors, An. dirus and $A n$. minimus were found at the two study sites of very low malaria transmission in Gia Lai Province, along with 9 secondary malaria vectors: An. aconitus, An. barbirostris s.l., An. harrisoni, An. maculatus, An. peditaeniatus,
An. philippinensis, An. sawadwongporni, An. sinensis, and An. vagus. Overall, 19 Anopheles species (14 taxa in IDR, and 18 taxa in IKD) were identified at the two study sites. From the same province, in Kong Chro district $(40 \mathrm{~km}$ from IDR and $70 \mathrm{~km}$ from IKD), Garros et al. [28] collected 11 Anopheles species, which included $A n$. dirus s.l., An. maculatus s.l., and $A n$. minimus s.l.. Identification of these mosquito specimens were based on morphology only, and thus it was not possible to identify which members of each species complex were found in their study. All Anopheles species found from the study by Garros et al. [28] were collected from the IKD and IDR sites in this study, except $A n$. jeyporiensis, and $A n$. nivipes. By combining the Anopheles species identified by Garros et al. [28] and those collected herein, a total of 21 Anopheles species have been identified from Gia Lai Province.

Anopheles diversity was greater in the forest sites (12 taxa in village sites, and 18 taxa in forest sites). Anopheles dirus and An. minimus, and the secondary malaria vectors, An. aconitus, An. barbirostris s.l., and An. sawadwongporni were more common in farm/forest sites. Although previous studies have incriminated $A n$. aconitus and An. sawadwongporni, and other Anopheles species (An. harrisoni, An. maculatus, An. pampanai, An. peditaeniatus An. philippinensis, An. sinensis) in maintaining malaria transmission in rural areas of the country $[10,29]$, still little is known about the role of secondary vectors in residual malaria transmission in rural areas.

Anopheles dirus and An. minimus were found only in forest sites. This might indicate the prevalence of 'external' malaria infection (infection outside the village) [8] observed in workers associated with forest sites in IDR (IDR health station, pers. comm.). Rainforests and secondary forests or plantations (rubber, fruits) provide appropriate breeding sites for An. dirus [30, 31]. The farm and forest sites in both communes are around $3 \mathrm{~km}$ and $10 \mathrm{~km}$ (IKD and IDR, respectively) away from the villages, and outside the flight range (approximately $1.5 \mathrm{~km}$ ) for An. dirus [30]. Therefore, the long distance between the breeding sites and the villages may be the reason for the absence of $A n$. dirus in village sites. The breeding sites for $A n$. minimus are usually ubiquitous [32], but perhaps in IKD this species is a habitat specialist, and thus found only in the farm/forest sites. Also, these sites can offer more host variety (i.e., cattle, chicken, dog). However, ecological studies are needed to clarify the ecology of An. minimus in Gia Lai Province.

Anopheles maculatus and An. sawadwongporni were the only vectors molecularly identified in the Maculatus Group. Anopheles sawadwongporni was the most collected species of the Maculatus Group in this study, making up $1.3 \%(240 / 18,835)$ of all collected species, and only a small number of $A n$. maculatus (IDR, $\mathrm{n}=1$; IKD, $\mathrm{n}=5$ ) 

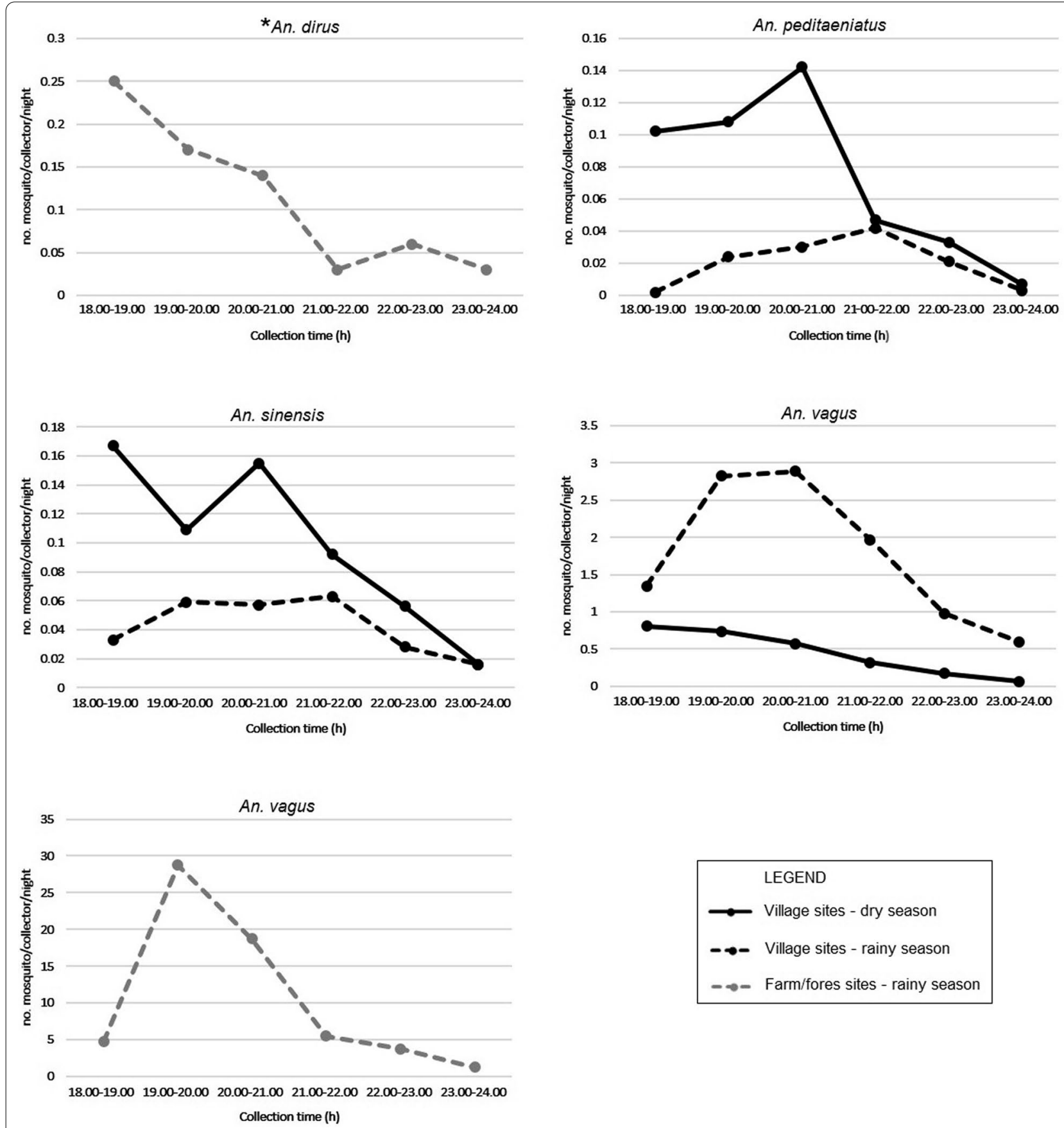

Fig. 2 Peak of host-seeking activity of Anopheles species in la DReh commune, Krong Pa district, Gia Lai Province, Vietnam. *An. dirus was collected using HDN, the remaining samples were collected around CS. HDN human-baited double net trap, CS cattle shed

were found in and around farm/forest areas. These two mosquito species are considered as secondary malaria vectors throughout Vietnam [10]. Anopheles maculatus was the dominant species collected in the southern province of Dak Nong [33] (170 km from IDR, $200 \mathrm{~km}$ from IKD), and was co-implicated with An. sawadwongporni as the primary vectors in Hang Chuon village, southwestern Quang Binh Province [10] (495 km from IDR, $465 \mathrm{~km}$ from IKD). The vector status of An. maculatus and $A n$. sawadwongporni in IDR and IKD is still unclear.

Anopheles vagus was the dominant species, followed by An. sinensis and An. peditaeniatus of both communes. 

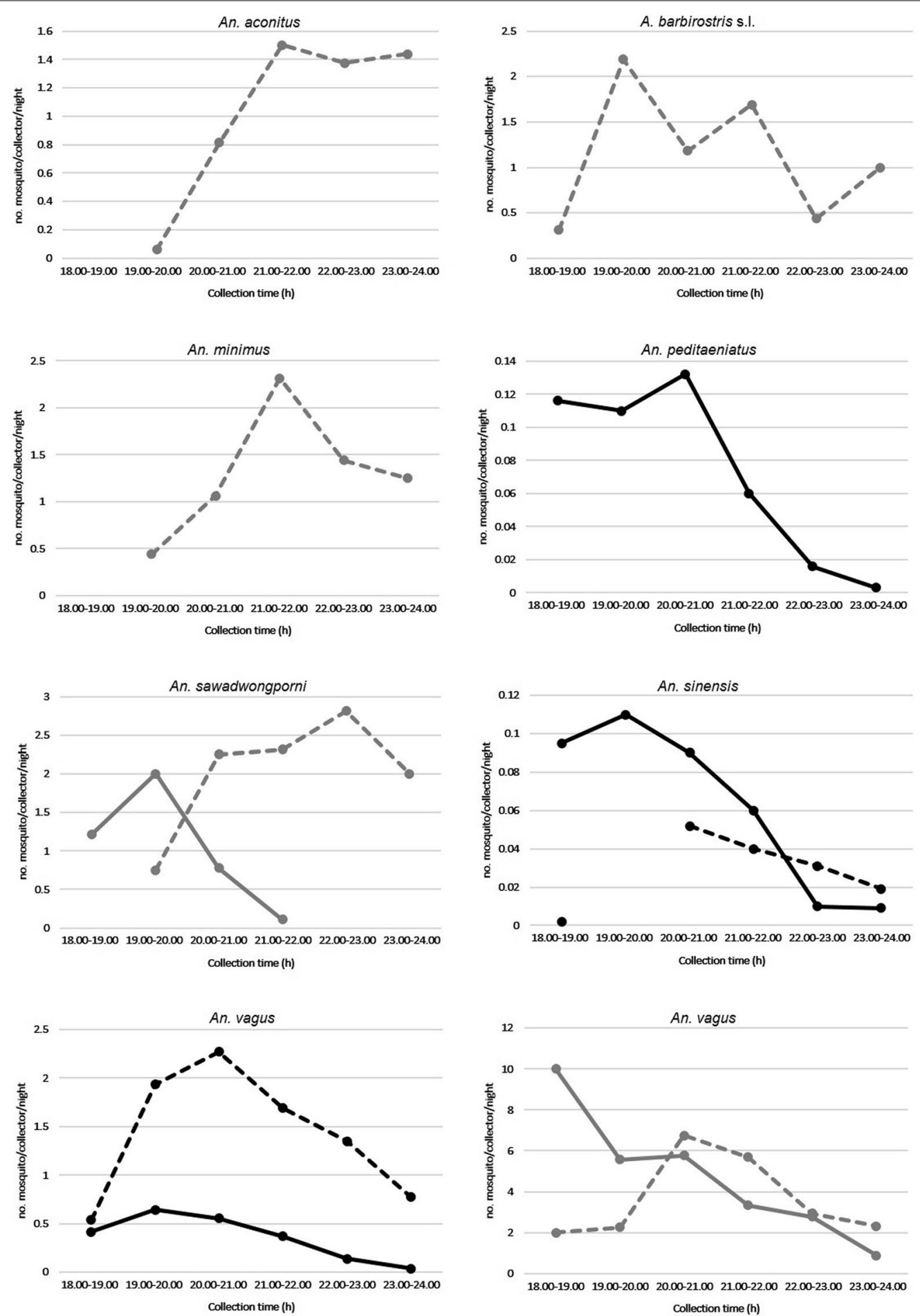

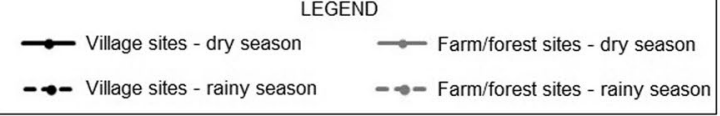

Fig. 3 Peak of host-seeking activity of Anopheles species collected around CS in KDam commune, la Pa district, Gia Lai Province, Vietnam. CS cattle shed 
Due to its ability to survive in small pools of turbid and organically polluted water [34], An. vagus has been found in high densities in countries of Southeast Asia (SEA) [8, 10, 28], including An. vagus positive for circumsporozoite protein (CSP) in mosquitoes in Bangladesh [35, 36]. However, there is no published information about the vector status of this species in Vietnam. Anopheles peditaeniatus have been found to be positive for CSP in Indonesia [37] and Thailand [38], and An. sinensis was involved with malaria transmission in China [39] and epidemics in Korea [40]. Anopheles peditaeniatus and An. sinensis were found to be positive for CPS in Quang Binh Province, Vietnam [10], with An. sinensis considered the major malaria vector for the province. The adaptable $A n$. vagus has been observed in different environments [10, 34] and because of its opportunistic and zoophilic behaviour $[8,10]$ limited research has been carried out on this species. Anopheles vagus appears not to play an important role in malaria transmission at the two study sites.

A high abundance of mosquitoes is expected in the rainy season, where more breeding sites are available and conditions are favourable for mosquito development. Indeed, more mosquitoes were collected during the rainy season compared to the dry season in this study, similar to reports from Thailand and Bangladesh [30, 41]. Similarly, an increased abundance of $A n$. dirus and $A n$. minimus has been observed in Vietnam during the rainy season between September and November [42]. Herein, An. minimus was present only during the rainy season, however, when combining the collections from the village and farm/forest areas of the two sites (IDR and IKD) most of the An. dirus $(74.4 \%, 67 / 90)$ were collected in the dry season. Rain was especially intense in the forest sites in both communes during the rainy season, and apparently flooded the breeding sites of An. dirus and other species that have more suitable habitats in the forest in IDR. On the other hand, An. minimus and the dominant $A n$. vagus were more common during the rainy season, probably due to the temporary breeding sites being more available in IKD for their development. Nevertheless, An. dirus was still found in the rainy season, as well as secondary malaria vectors collected throughout both seasons. This suggests that favourable conditions for vector development exist year-round, which ensures the maintenance of malaria parasites. Consequently, the epidemiologic triad of host (human, animal), agent (Plasmodium + Anopheles), and environment conditions contribute to the maintenance of malaria transmission in the study areas.

\section{Collection and behaviour of malaria vectors}

Due to logistical limitations, the distribution of traps in the two communes and the number of collections were not homogeneous. The limitations included difficulty in setting up traps, arranging and maintaining cows in farm and forest sites, and loss of LTs. Unfortunately, many traps were knocked over and found empty, probably because of animal movement during the night. Also, during the collection, the weather impacted sample collection, with heavy rain and flooding which made it difficult to collect the mosquitoes at the communes. Nonetheless, specific comparisons of the mosquitoes collected for each collection method was carried out.

Studies of malaria vectors in SEA have used a variety of methods to collect mosquitoes, including human baits (human landing catches-HLC and HDN) $[8,10,15,24$, 43], animal baits (buffalo, cattle) [8, 10, 15, 33], and LTs $[33,44-46]$ to collect mosquitoes. Light traps are a costeffective method for mosquito collection; however, the efficacy varies by location [45, 47]. Another cost-effective method for the collection of vector species is HDN, an alternative to HLC, which eliminates exposing collectors to mosquito bites [24]. Herein, a high density and diversity of mosquitoes were collected using CS. In other studies, similar results were reported using CS, with a high diversity of mosquitoes collected including primary and secondary malaria vectors $[10,28,48]$. Despite the simultaneous collection using human (HDN) and cattle bait (CS), it was not possible to calculate the anthropophilic index due to the heterogeneous distribution of traps and number of collections, and the prominent zoophilic behaviour observed of all Anopheles species, except An. dirus.

Anopheles dirus was observed to be the most anthropophilic species in this study and is consistent with other studies conducted in SEA [13, 30, 31, 33, 49]. However, there are reports of An. dirus with strong zoophilic behaviour in Kanchanaburi Province, Thailand [50] suggesting some variance in behaviour across SEA. Anopheles minimus, together with many secondary vectors identified in this study, showed zoophilic behaviour, which has been similarly observed in other regions in Vietnam and neighbouring countries $[10,15,51-54]$. Anopheles minimus host-seeking behaviour is similarly variable with anthropophilic behaviour observed in Khanh Hoa Province (Vietnam) and Vientiane Province (Laos) while Van Bortel et al. [32] reported heterogeneity in host choice. There are reports An. minimus are attracted to cattle when abundant, but are attracted to humans when catthe are scarce $[15,32,55]$. In this study An. minimus was found exclusively in farm/forest areas in IKD, where there were many types of host, such as cattle, chicken and dogs. The close proximity of cattle to household areas has been associated with an increase in malaria prevalence $[56,57]$ suggesting a relationship to host-seeking behaviour and horticulture practices. A future study of blood 
meals in An. minimus is required to better understand the impact of host choice on vector survival and reproduction in areas of malaria transmission.

Do Manh et al. [10] conducted a malaria survey in Quang Binh Province (Vietnam) using paired collections of buffalo and humans (with $15 \mathrm{~m}$ of distance between them), and observed that $97.4 \%(4,489 / 4,610)$ of the anopheline collected were attracted to buffalo and only $2.6 \%(121 / 4,610)$ to humans using HLC. The authors suggested that animals (buffalo/cattle) around human settlements may play a zooprophylactic role [10]. In this study, it was observed that anopheline were more attracted to animals than human, similar to Do Manh et al. findings [10]. To reduce vector density and longevity, Do Manh et al. [10] proposed a strategy of maintaining animal baits (cattle, buffalo) around human habitation and implementing barrier spraying to supplement other intervention methods such as IRS and the use of LLIN.

The early host-seeking time of 18.00 to 19.00 observed for An. dirus, An. sinensis and An. vagus coincided with human activities outdoors. This study implies that the use of LLIN after 21.00 will have limited impact on reducing Anopheles bites. Villagers and forest workers usually go to bed after 21.00 (TQN pers. obsv.), therefore, the use of LLIN in areas where vectors bite outdoors and/or early in the evening when people are still active will not be very effective [58]. Additionally, some bed nets appeared worn with large holes or gashes, limiting their ability to protect users. LLINs are a critical component of the NMCP, however, there are reports of limited use despite nearuniversal availability [11, 12, 22]. Perhaps, an alternative to support the strategies to prevent malaria transmission could include the distribution of repellent or repellent clothing (treated coveralls) to the villagers-workers in addition to the LLINs as cost-effective methods for protection against malaria vectors. Moreover, additional research based on practical personal protection tools (i.e., those do not require behaviour change and are easy to use) is required to eliminate residual malaria transmission [5] in these areas.

\section{Conclusions}

Nineteen Anopheles species were identified at the two study sites in Gia Lai Province, including two primary malaria vectors, $A n$. dirus and An. minimus and 9 secondary malaria vectors. During the course of this study, An. dirus displayed anthropophilic preferences, whereas $A n$. minimus and a number of the secondary vectors displayed zoophilic preferences for host. The observed results provided information on the diversity, seasonal prevalence and behaviour of Anopheles in the study sites. Moreover, the peak (18.00 to 23.00)
Anopheles host-seeking activity was observed in this study highlighting the future need to focus on Anopheles behaviour in this region of the central highlands of Vietnam.

\section{Abbreviations}

CDC: Center for Disease Control and Prevention; CSP: Circumsporozoite protein; CS: Collection around cattle shed; HDN: Human-baited double net trap; HLC: Human landing catches; IDR: la DReh commune; IKD: Ia KDam commune; ITN: Insecticide-threated net; LLIN: Long-lasting insecticidal net; LT: Light trap; NMCP: National Malaria Control Programme; SEA: Southeast Asia; UV: Ultraviolet.

\section{Supplementary Information}

The online version contains supplementary material available at https://doi. org/10.1186/s12936-021-03941-6.

Additional file 1. Number of Anopheles specimens collected indoor and outdoor using HDN and LT in village and farm and forest sites in la DReh commune, Krong Pa district, and in la KDam commune, la Pa district, Gia Lai Province, Vietnam.

Additional file 2. A. HDN rates (number of mosquito/collector/night) for malaria vectors collected in village and farm/forest sites during dry and rainy seasons in la DReh commune, Krong Pa district, Gia Lai Province, Vietnam. B. CS rates (number of mosquito/collector/night) for malaria vectors collected in village and farm/forest sites during dry and rainy seasons in la DReh commune, Krong Pa district, Gia Lai Province, Vietnam

Additional file 3. A. HDN rates (number of mosquito/collector/night) for malaria vectors collected in village and farm/forest sites during dry and rainy seasons in la KDam commune, la Pa district, Gia Lai Province, Vietnam B. CS rates (number of mosquito/collector/night) for malaria vectors collected in village and farm/forest sites during dry and rainy seasons in la KDam commune, la Pa district, Gia Lai Province, Vietnam.

\section{Acknowledgements}

We are grateful to Duong Thi Hoa, Dinh Thi Khuya, Nguyen Tien Cuong, Ly Hong Van, Le Anh Tuan, Le Xuan Xung and Nguyen Thi Hong Van from the Military Institute of Preventive Medicine; to Phan Vu Ho, Le Hai Binh, Le Thi Luong and Dang Thanh Tinh from the Central of Protective Malaria Parasite and Entomology, Gia Lai Province for helping us in the field work. Our sincere thanks to Nguyen Thi Phuong Hoa, Dieu Nguyen Linh, Diana Paola Naranjo, Carlo Traverso and Nicole Zdrojewski from Vysnova Partners for facilitating this research. Many thanks to Dr. Rossana Veronica Mendoza Lopez from Instituto do Cancer do Estado de Sao Paulo, Brazil for her guidance on statistics analysis. We appreciate the reviewers for providing helpful comments and suggestions.

\section{Disclaimer}

The views expressed in this publication are those of the author and do not necessarily reflect the official policy or position of the Department of the Navy, Department of Defense, nor the U.S. Government, the Vietnam People's Army and those of the Australian Defence Force, Joint Health Command or any extant Australian Defence Force policy. JCH and NJM are military Service members. This work was prepared as part of their official duties. Title 17, U.S.C., $\S 105$ provides that copyright protection under this title is not available for any work of the U.S. Government. Title 17, U.S.C., §101 defines a U.S. Government work as a work prepared by a military Service member or employee of the U.S. Government as part of that person's official duties.

\section{Authors' contributions}

TQN, NJM, and JCH conceived the study. TQN and WC performed the molecular experiments with input from MTM. TQN, MDN, VXP, and HMR contributed to the field collection. TQN, MDE, WC, NJM, JCH, and MTM wrote the main manuscript text. All authors read and approved the final manuscript. 


\section{Funding}

This study was supported by the Defense Malaria Assistance Program with funds from the Defense Health Agency Research and Development Program (work unit number D1430). The Military Institute of Preventive Medicine (MIPM) also provided support for field work and sample analysis.

\section{Availability of data and materials}

All data generated or analyzed during the current study are included in this published article.

\section{Declarations}

\section{Ethics approval and consent to participate}

Not applicable.

\section{Consent for publication}

Not applicable.

\section{Competing interests}

The authors declare that they have no competing interests.

\section{Author details}

${ }^{1}$ Vietnam People's Army Military, Institute of Preventive Medicine, Hanoi, Vietnam. ${ }^{2}$ Gia Lai Center for Disease Control (CDC), Pleiku, Gia Lai, Vietnam. ${ }^{3}$ Australian Defence Force Malaria and Infectious Disease Institute, Brisbane, Australia. ${ }^{4}$ US Naval Medical Research Unit-Two (NAMRU-2), Singapore, Singapore. ${ }^{5}$ Vysnova Partners Inc, Landover, MD, USA. ${ }^{6}$ Department of Entomology, Natural Museum of Natural History, Smithsonian Institution, Museum Support Center, Suitland, MD, USA.

\section{Received: 15 March 2021 Accepted: 4 October 2021}

Published online: 16 October 2021

\section{References}

1. WHO. National malaria programme review_Viet Nam. Geneva: World Health Organization, Regional Office for the Western Pacific; 2018.

2. Schuftan C. A story to be shared: the successful fight against malaria in Vietnam. World Health Organization WPRO and the global Roll Back Malaria Programme; 2000. http://www.afronets.org. Accessed 1 July 2020.

3. Ettling MB. The control of malaria in Viet Nam from 1980 to 2000: what went right? Geneva: World Health Organization, Regional Office for the Western Pacific; 2002.

4. Hung LQ, Vries PJ, Giao PT, Nam NV, Binh TQ, Chong MT, et al. Control of malaria: a successful experience from Viet Nam. Bull World Health Organ. 2002;80:660-5.

5. Edwards HM, Chinh VD, Duy BL, Thanh PV, Thang ND, Trang DM, et al. Characterizing residual malaria transmission in forested areas with low coverage of core vector control in central Viet Nam. Parasit Vectors. 2019;12:454.

6. Erhart A, Thang ND, Hung NQ, Toi LV, Hung LX, Tuy TQ, et al. Forest malaria in Vietnam: a challenge for control. Am J Trop Med Hyg. 2004;70:110-8.

7. Erhart A, Thang ND, Ky PV, Tinh TT, Overmeir CV, Speybroeck N, et al. Epidemiology of forest malaria in central Vietnam: a large scale crosssectional survey. Malar J. 2005:4:58.

8. Sanh NH, Van Dung N, Thanh NX, Trung TN, Van Co T, Cooper RD. Forest malaria in central Vietnam. Am J Trop Med Hyg. 2008;79:652-4.

9. Pongvongsa T, Ha H, Thanh L, Marchand RP, Nonaka D, Tojo B, et al. Joint malaria surveys lead towards improved cross-border cooperation between Savannakhet Province, Laos and Quang Tri Province, Vietnam. Malar J. 2012;11:262.

10. Do Manh C, Beebe NW, Van VN, Quang TL, Lein CT, Nguyen DV, et al. Vectors and malaria transmission in deforested, rural communities in north-central Vietnam. Malar J. 2010;9:259.

11. Canavati SE, Kelly GC, Quintero CE, Vo TH, Tran LK, Ohrt C, et al. Risk factor assessment for clinical malaria among forest-goers in a pre-elimination setting in Phu Yen Province, Vietnam. Malar J. 2019;18:435.

12. Canavati SE, Kelly GC, Quintero CE, Vo TH, Tran LK, Ngo TD, et al. Targeting high risk forest goers for malaria elimination: a novel approach for investigating forest malaria to inform program intervention in Vietnam. BMC Infect Dis. 2020;20:757.

13. Hii J, Rueda LM. Malaria vectors in the Greater Mekong Subregion: overview of malaria vectors and remaining challenges. Southeast Asian J Trop Med Public Health. 2013;44:73-165.

14. Nguyen VD. Checklist of the known species of Culicidae found in Vietnam. National Scientific. In: 6th conference on ecology and biological resources. Vietnam. 2015:504-9.

15. Trung HD, Van Bortel W, Sochantha T, Keokenchanh K, Briët OJT, Coosemans M. Behavioural heterogeneity of Anopheles species in ecologically different localities in Southeast Asia: a challenge for vector control. Trop Med Int Health. 2005;10:251-62.

16. WHO. Anopheline species complexes in South and South-East Asia. Geneva: World Health Organization, Regional office for South-East Asia; 2007.

17. Van Bortel W, Trung HD, Roelants P, Harbach RE, Backeljau T, Coosemans M. Molecular identification of Anopheles minimus s.l. beyond distinguishing the members of the complex. Insect Mol Biol. 2000;9:335-40.

18. Walton C, Handley JM, Kuvangkadilok C, Collins FH, Harbach RE, Baimai $V$, et al. Identification of five species of the Anopheles dirus complex from Thailand, using allele-specific polymerase chain reaction. Med Vet Entomol. 1999;13:24-32.

19. Manguin S, Kengne P, Sonnier L, Harbach RE, Baimai V, Trung HD, et al. SCAR markers and multiplex PCR-based identification of isomorphic species in the Anopheles dirus complex in Southeast Asia. Med Vet Entomol. 2002;16:46-54.

20. Walton C, Somboon P, O'Loughlin SM, Zhang S, Harbach RE, Linton YM, et al. Genetic diversity and molecular identification of mosquito species in the Anopheles maculatus group using the ITS2 region of rDNA. Infect Genet Evol. 2007;7:93-102.

21. Dusfour I, Blondeau J, Harbach RE, Vythilingham I, Baimai V, Trung HD, et al. Polymerase chain reaction identification of three members of the Anopheles sundaicus (Diptera: Culicidae) complex, malaria vectors in Southeast Asia. J Med Entomol. 2007;4:723-31.

22. Grietens KP, Xuan XN, Ribera JM, Duc TN, Van Bortel W, Ba NT, et al. Social determinants of long lasting insecticidal hammock-use among the rai-gai ethnic minority in Vietnam: implications for forest malaria control. PLOS ONE. 2012;7:e29991.

23. WHO. Malaria surveillance, monitoring and evaluation: a reference manual. Geneva: World Health Organization; 2018.

24. Tangena JAA, Thammavong P, Hiscox A, Lindsay SW, Brey PT. The human-baited double net trap: an alternative to human landing catches for collecting outdoor biting mosquitoes in Lao PDR. PLOS ONE. 2015;10:e0138735.

25. National Institute of Malariology, Parasitology and Entomology (NIMPE). Keys to identify the Anopheles mosquitoes (adults-pupae-larvae). Hanoi: Department of Entomology_National Institute of Malariology, Parasitology and Entomology; 2008.

26. Garros C, Koekemoer LL, Coetzee M, Coosemans M, Manguin S. A single multiplex assay to identify major malaria vectors within the African Anopheles funestus and the Oriental An. minimus groups. Am J Trop Med Hyg. 2004;70:583-90.

27. Huong NT, Sonthayanon P, Ketterman AJ, Panyim S. A rapid polymerase chain reaction based method for identification of the Anopheles dirus sibling species. Southeast Asian J Trop Med Public Health. 2001;32:615-20.

28. Garros C, Van Nguyen C, Trung HD, Van Bortel W, Coosemans M, Manguin S. Distribution of Anopheles in Vietnam, with particular attention to malaria vectors of the Anopheles minimus complex. Malar J. 2008;7:11.

29. Obsomer V, Defourny P, Coosemans M. The Anopheles dirus complex: spatial distribution and environmental drivers. Malar J. 2007;6:26.

30. Rosenberg R, Maheswary NP. Forest malaria in Bangladesh. II. transmission by Anopheles dirus. Am J Trop Med Hyg. 1982;31:183-91.

31. Rosenberg R, Andre RG, Somchit L. Highly efficient dry season transmission of malaria in Thailand. Trans R Soc Trop Med Hyg. 1990;84:22-8.

32. Van Bortel W, Trung HD, Sochantha T, Keokenchan K, Roelants P, Backeljau $T$, et al. Eco-ethological heterogeneity of the members of the Anopheles minimus complex (Diptera: Culicidae) in Southeast Asia and its consequences for vector control. J Med Entomol. 2004;41:366-74.

33. Ngo CT, Dubois G, Sinou V, Parzy D, Le HQ, Harbach RE, et al. Diversity of Anopheles mosquitoes in Binh Phuoc and Dak Nong Provinces of Vietnam and their relation to disease. Parasit Vectors. 2014;7:316. 
34. Rueda LM, Pecor JE. Updated distribution records for Anopheles vagus (Diptera: Culicidae) in the Republic of Philippines, and considerations regarding its secondary vector roles in Southeast Asia. Trop Biomed. 2011;28:181-7.

35. Maheswary NP, Majumdar S, Chowdhury AR, Faruque MS, Montanari RM. Incrimination of An. vagus Donitz 1902 as an epidemic malaria vector in Bangladesh. Indian J Malariol. 1994;24:776-8.

36. Alam MS, Khan MGM, Chaudhury N, Deloer S, Nazib F, Bangali AM, et al. Prevalence of anopheline species and their Plasmodium infection status in epidemic-prone border areas of Bangladesh. Malar J. 2010;9:15.

37. Sugiarto, Kesumawati Hadi U, Soviana S, Hakim L. Confirmation of Anopheles peditaeniatus and Anopheles sundaicus as malaria vectors (Diptera: Culicidae) in Sungai Nyamuk Village, Sebatik Island North Kalimantan, Indonesia using an enzyme-linked immunosorbent assay. J Med Entomol. 2016;53:1422-4.

38. Gingrich JB, Weatherhead A, Sattabongkot J, Pilakasiri C, Wirtz RA. Hyperendemic malaria in a Thai village: dependence of year-round transmission on focal and seasonally circumscribed mosquito (Diptera: Culicidae) habitats. J Med Entomol. 1990;27:1016-26.

39. Sleigh AC, Liu XL, Jackson S, Li P, Shang LY. Resurgence of vivax malaria in Henan Province. China Bull World Health Organ. 1998;76:265-70.

40. Lee JS, Lee WJ, Cho SH, Ree HI. Outbreak of vivax malaria in areas adjacent to the demilitarized zone, South Korea, 1998. Am J Trop Med Hyg. 2002;66:13-7.

41. Sungvornyothin S, Kongmee M, Muenvorn V, Polsomboon S, Bangs MJ, Prabaripai A, et al. Seasonal abundance and blood feeding activity of Anopheles dirus sensu lato in western Thailand. J Am Mosq Control Assoc. 2009;25:425-30.

42. National Institute of Malariology, Parasitology and Entomology (NIMPE). Final report. Survey on malaria vectors and vector control activities in high malaria endemic areas of Gia Lai and Khanh Hoa Provinces. Hanoi: NIMPE, Ministry of Health; 2016.

43. Trung HD, Van Bortel W, Sochantha T, Keokenchanh K, Quang NT, Cong LD, et al. Malaria transmission and major malaria vectors in different geographical areas of Southeast Asia. Trop Med Int Health. 2004;9:230-7.

44. Rattanarithikul R, Konishi E, Linthicum KJ. Observations on nocturnal biting activity and host preference of anophelines collected in southern Thailand. J Am Mosq Control Assoc. 1996;12:52-7.

45. Singh N, Mishra AK. Efficacy of light-traps in sampling malaria vectors in different ecological zones in central India. SE Asian J Trop Med. 1997;28:196-202.

46. Schultz GW, Hayes CG. Ecology of mosquitoes (Diptera: Culicidae) at site endemic with Japanese encephalitis on Luzon, Republic of the Philippines. SE Asian J Trop Med. 1993;24:157-64.

47. Gunasekaran K, Jambulingam P, Sadanandane C, Sahu SS, Das PK. Reliability of light trap sampling for Anopheles fluviatilis, a vector of malaria. Acta Trop. 1994;58:1-11.
48. St. Laurent B, Oy K, Miller B. Cow-baited tents are highly effective in sampling diverse Anopheles malaria vectors in Cambodia. Malar J. 2016;15:440.

49. Vythilingam I, Phetsouvanh R, Keokenchanh K, Yengmala V, Vanisaveth V, Phompida S, et al. The prevalence of Anopheles (Diptera: Culicidae) mosquitoes in Sekong Province, Lao PDR in relation to malaria transmission. Trop Med Int Health. 2003;8:525-35.

50. Tananchai C, Tisgratog R, Juntarajumnong W, Grieco JP, Manguin S, Prabaripai $A$, et al. Species diversity and biting activity of Anopheles dirus and Anopheles baimaii (Diptera: Culicidae) in a malaria prone area of western Thailand. Parasit Vectors. 2012;5:211.

51. Kobayashi J, Nambanya S, Miyagi I, Vanachone B, Manivong K, Koubouchan T, et al. Collection of anopheline mosquitoes in three villages endemic for malaria in Khammouane, Lao PDR. Southeast Asian Trop Med Public Health. 1997;28:615-20.

52. Kobayashi J, Somboon P, Keomanila H, Inthavongsa S, Nambanya S, Inthakone S, et al. Malaria prevalence and brief entomological survey in a village surrounded by rice fields in Khammouan Province, Lao PDR. Trop Med Int Health. 2000;5:17-21.

53. Toma T, Miyagi I, Okazawa T, Kobayashi J, Saita S, Tuzuki A, et al. Entomological surveys of the malaria in Khammouane Province, Lao PDR, in 1999 and 2000. Southeast Asian J Trop Med Public Health. 2002;33:532-46.

54. Muenworn V, Sungvomyothin S, Kongmee M, Polsomboom S, Bangs MJ, Akrathanakul $\mathrm{P}$, et al. Biting activity and host preference of the malaria vectors Anopheles maculatus and Anopheles sawadwongporni (Diptera: Culicidae) in Thailand. J Vector Ecol. 2009;34:62-9.

55. Ismail IAH, Phinichpongse S, Boonrasri P. Responses of Anopheles minimus to DDT residual spraying in a cleared forested foothill area in central Thailand. Acta Trop. 1978;35:69-82.

56. Hewitt S, Kamal M, Nasir M, Rowland M. An entomological investigation of likely impact of cattle ownership on malaria in an Afghan refugee camp in the North West Frontier Province of Pakistan. Med Vet Entomol. 1994:8:160-4.

57. Bouma M, Rowland M. Failure of passive zooprophylaxis: cattle ownership in Pakistan is associated with a higher prevalence of malaria. Trans R Soc Trop Med Hyg. 1995;82:351-3.

58. Van Bortel W, Trung HD, le Hoi X, Van Ham N, Van Chut N, Luu ND, et al. Malaria transmission and vector behaviour in a forested malaria focus in central Vietnam and the implications for vector control. Malar J. 2010;9:373.

\section{Publisher's Note}

Springer Nature remains neutral with regard to jurisdictional claims in published maps and institutional affiliations.
Ready to submit your research? Choose BMC and benefit from:

- fast, convenient online submission

- thorough peer review by experienced researchers in your field

- rapid publication on acceptance

- support for research data, including large and complex data types

- gold Open Access which fosters wider collaboration and increased citations

- maximum visibility for your research: over $100 \mathrm{M}$ website views per year

At BMC, research is always in progress.

Learn more biomedcentral.com/submissions 